\title{
Pathophysiology and aetiology of impaired fasting glycaemia and impaired glucose tolerance: does it matter for prevention and treatment of type 2 diabetes?
}

\author{
K. Færch • K. Borch-Johnsen • J. J. Holst • A. Vaag
}

Received: 7 April 2009 / Accepted: 16 June 2009 / Published online: 10 July 2009

(C) Springer-Verlag 2009

\begin{abstract}
Prior to the development of type 2 diabetes, glucose levels increase into the prediabetic states of isolated impaired fasting glycaemia (i-IFG), isolated impaired glucose tolerance (i-IGT), or combined IFG/IGT. A better understanding of the aetiology and pathophysiology of the prediabetic states might give a basis for the development of individualised prevention and treatment strategies for type 2 diabetes. Several studies have examined mechanisms and potential aetiological factors leading to the development of the different prediabetic states. The pathophysiology of iIFG seems to include the following key defects: reduced hepatic insulin sensitivity, stationary beta cell dysfunction and/or chronic low beta cell mass, altered glucagon-like peptide-1 secretion and inappropriately elevated glucagon secretion. Conversely, the prediabetic state i-IGT is characterised by reduced peripheral insulin sensitivity, nearnormal hepatic insulin sensitivity, progressive loss of beta cell function, reduced secretion of glucose-dependent insulinotropic polypeptide and inappropriately elevated glucagon secretion. Individuals developing combined IFG/ IGT exhibit severe defects in both peripheral and hepatic insulin sensitivity as well as a progressive loss of beta cell function. The aetiologies of i-IFG and i-IGT also seem to
\end{abstract}

\footnotetext{
K. Færch $(\bowtie) \cdot$ K. Borch-Johnsen $\cdot$ A. Vaag

Steno Diabetes Center,

Niels Steensens Vej 2,

2820 Gentofte, Denmark

e-mail: krif@steno.dk

K. Borch-Johnsen

University of Aarhus,

Aarhus, Denmark

J. J. Holst

Department of Biomedical Sciences, University of Copenhagen, Copenhagen, Denmark
}

differ, with i-IFG being predominantly related to genetic factors, smoking and male sex, while i-IGT is predominantly related to physical inactivity, unhealthy diet and short stature. Since the transition from the prediabetic states to overt type 2 diabetes is characterised by a non-reversible vicious cycle that includes severe deleterious effects on glucose metabolism, there are good reasons to use the wellestablished aetiological and pathophysiological differences in $\mathrm{i}$-IFG, $\mathrm{i}-\mathrm{IGT}$ and IFG/IGT to design individualised preventive strategies.

Keywords Beta cell dysfunction · Environmental factors . Genetic factors $\cdot$ Impaired fasting glycaemia . Impaired glucose tolerance $\cdot$ Insulin resistance . Pathophysiology · Prevention · Review · Treatment

$\begin{array}{ll}\text { Abbreviations } \\ \text { 2hPG } & \text { 2 h plasma glucose } \\ \text { EGP } & \text { Endogenous glucose production } \\ \text { FPG } & \text { Fasting plasma glucose } \\ \text { GIP } & \text { Glucose-dependent insulinotropic polypeptide } \\ \text { GLP-1 } & \text { Glucagon-like peptide-1 } \\ \text { IFG/IGT } & \begin{array}{l}\text { Combined impaired fasting glycaemia and } \\ \text { impaired glucose tolerance }\end{array} \\ \text { i-IFG } & \text { Isolated impaired fasting glycaemia } \\ \text { i-IGT } & \text { Isolated impaired glucose tolerance } \\ \text { NGT } & \text { Normal glucose tolerance }\end{array}$

Introduction

The key hormonal defects responsible for hyperglycaemia in type 2 diabetes are decreased insulin secretion [1] and elevated glucagon secretion $[2,3]$, but also the secretion 
and action of the gut incretin hormones glucagon-like peptide-1 (GLP-1) and glucose-dependent insulinotropic polypeptide (GIP) are altered in type 2 diabetes [4]. These defects contribute to elevated endogenous glucose production (EGP) from the liver [5] and kidney [6], which in combination with peripheral (muscle) insulin resistance [1] lead to hyperglycaemia. In addition, adipose tissue affects glucose metabolism through altered release of adipocytokines [7] and NEFAs into the bloodstream [8]. Also hypothalamic insulin signalling affects regulation of EGP and hepatic insulin resistance in rodents [9], underscoring the concept of type 2 diabetes as a multiple organ disease [10].

Prior to the development of type 2 diabetes, glucose levels increase into the prediabetic states of isolated impaired fasting glycaemia (i-IFG), isolated impaired glucose tolerance (i-IGT), or combined IFG/IGT. The predominant metabolic abnormality of the specific prediabetic state is likely to track into the development of type 2 diabetes, giving rise to different type 2 diabetes phenotypes with potentially different requirements for prevention and treatment. A better understanding of the aetiology and pathophysiology of the prediabetic states might give a basis for the development of individualised prevention and treatment strategies for type 2 diabetes. This article reviews mechanisms and potential aetiological factors leading to the development of the prediabetic states i-IFG, i-IGT and IFG/ IGT, and ultimately to type 2 diabetes. Furthermore, the article addresses the possibility of using this pathophysiological and aetiological knowledge in optimising individualised prevention and treatment of type 2 diabetes.

\section{Pathophysiology of i-IFG, i-IGT and IFG/IGT}

Muscle

Peripheral insulin sensitivity is important for lowering blood glucose levels after an OGTT, since most of the glucose in this period is taken up by skeletal muscle [11]. Conversely, in the fasting state, approximately $50 \%$ of glucose uptake occurs in the insulin-insensitive brain tissue, while mainly fatty acid oxidation is responsible for energy expenditure in muscle tissue [12]. Therefore, insulin sensitivity in muscle tissue will not markedly influence plasma glucose levels in the fasting state. Studies using euglycaemic-hyperinsulinaemic clamp techniques in prediabetic individuals have supported this. They found that peripheral insulin sensitivity is decreased in individuals with i-IGT, while it is normal in those with i-IFG [13-18] (Fig. 1a).

In large epidemiological studies where insulin sensitivity has been estimated by use of glucose and insulin levels measured during an OGTT, we and others also found reduced insulin sensitivity in individuals with i-IFG [1921] (Fig. 2a). The discrepancy between the findings from the clamp and the OGTT studies is likely to be caused by the fact that the liver plays a larger role during the OGTT than during the clamp. During a euglycaemic-hyperinsulinaemic clamp, EGP is almost fully suppressed [22], and clamp-derived estimates of insulin sensitivity therefore primarily reflect insulin action in skeletal muscle. Conversely, during oral glucose ingestion, insulin levels are lower [13] and EGP is less suppressed [12]. Accordingly, estimates of insulin sensitivity derived from post-OGTT levels of glucose and insulin may reflect both hepatic and peripheral insulin action. In support of this, a study [23] recently demonstrated that hepatic insulin sensitivity accounted for one-third, whereas peripheral insulin sensitivity accounted for two-thirds of glucose disposal after a meal in healthy individuals.

\section{Liver}

Elevated EGP from the liver, caused by increased gluconeogenesis [24], is a hallmark of type 2 diabetes. In individuals with $\mathrm{i}-\mathrm{IFG}$, the absolute level of EGP does not appear to be elevated [13, 14, 25]. However, two studies $[14,25]$ found elevated basal insulin levels in individuals with i-IFG, and they suggested that EGP was disproportionately elevated. This indicates that hepatic insulin resistance is a key defect in i-IFG. We were not able to demonstrate hepatic insulin resistance in individuals with iIFG when studied by use of tracer technique [13]. A likely explanation is that our study participants had progressed from normal glucose tolerance (NGT) to i-IFG within 5 years, and therefore they did not yet have significantly elevated fasting insulin levels. However, we found that HOMA index of insulin sensitivity, predominantly reflecting hepatic insulin sensitivity, was decreased in individuals with early detected i-IFG [19] (Fig. 2b). Individuals with iIGT do not have elevated EGP or hepatic insulin resistance $[13,14]$, which is most probably related to their normal fasting glucose levels.

\section{Pancreas}

Insulin secretion Several studies have demonstrated decreased insulin secretion (as indicative of beta cell dysfunction) in prediabetic individuals with i-IFG [13-15] (Fig. 1b). Recently, we showed that individuals who progressed from NGT to i-IFG within 5 years were characterised by a constitutive, stationary defective beta cell function or chronic reduced beta cell mass [26], which was already present before fasting hyperglycaemia was demonstrated [19] (Fig. 2c,d). Continued beta cell apoptosis 


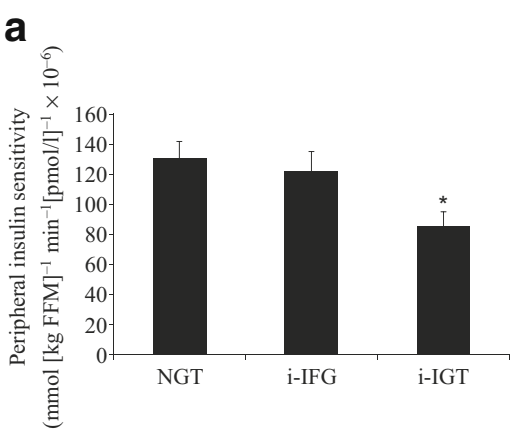

b

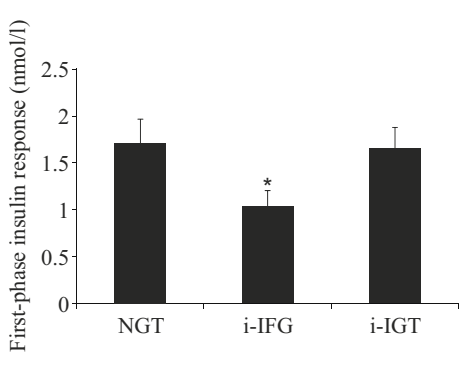

C

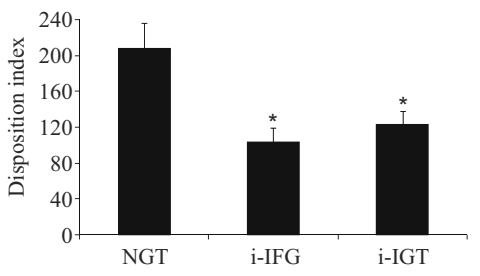

Fig. 1 a Peripheral insulin sensitivity (mean+SE) during a euglycaemic-hyperinsulinaemic clamp; b first-phase insulin response (geometric mean $+\mathrm{SE}$ ) during an IVGTT; and $\mathbf{c}$ disposition index (first-phase insulin response $\times$ peripheral insulin sensitivity; geometric mean $\pm \mathrm{SE}$, arbitrary unit) in 20 individuals with NGT, 18 with i-IFG and 28 with i-IGT. ${ }^{*} p<0.05$ vs NGT and i-IFG (a); ${ }^{*} p<0.05$ vs NGT and i-IGT (b); ${ }^{*} p<0.05$ vs NGT (c). Adapted from Færch et al. [13]. FFM, fatfree mass is not likely to cause the defective beta cell function, since this would lead to a progressive and not a stationary loss of beta cell function. However, if individuals with i-IFG develop peripheral insulin resistance, beta cell function or mass may progressively decline in these individuals in the same manner as in individuals with i-IGT [19], IFG/IGT $[19,27]$ and type 2 diabetes $[1,28]$.

A major determinant for regulation of beta cell mass and function is glucose concentration [29]. In the early states of impaired glucose regulation, pancreatic beta cells adapt to insulin resistance (i.e. increased blood glucose levels) by increasing mass and function [29]. However, by calculating
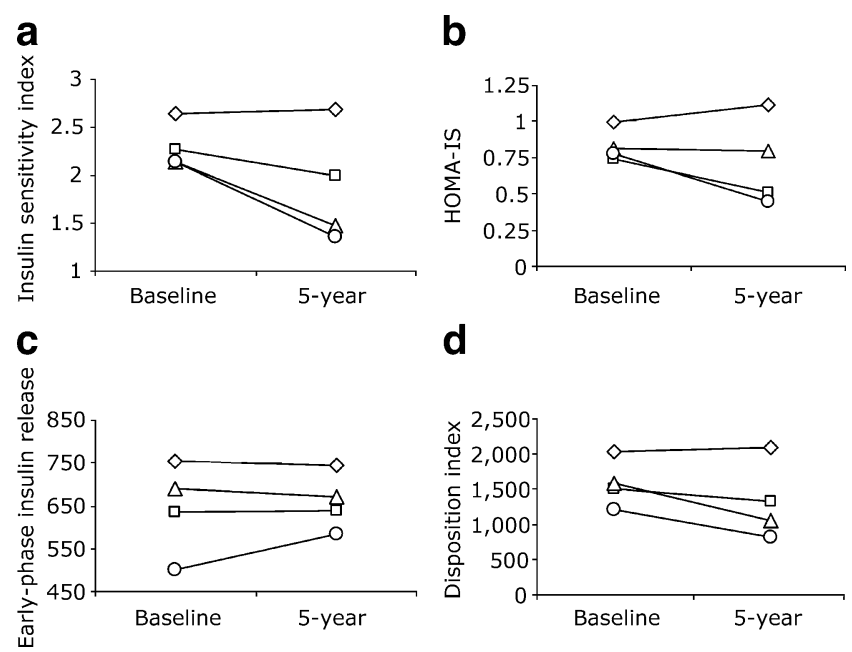

Fig. 2 a Insulin sensitivity index; b HOMA-insulin sensitivity (HOMA-IS); $\mathbf{c}$ early-phase insulin release and $\mathbf{d}$ disposition index of beta cell function in individuals with NGT at baseline who maintained NGT status $(n=2,842$, diamonds) or who progressed to i-IFG ( $n=83$, squares), i-IGT ( $n=192$, triangles) or IFG/IGT ( $n=28$, circles) within 5 years. Data are medians (arbitrary units). $p<0.05$ for differences in 5-year changes: i-IGT vs NGT, IFG/IGT vs NGT (a); i-IFG vs NGT, IFG/IGT vs NGT, i-IGT vs i-IFG, IFG/IGT vs i-IGT (b); i-IGT vs NGT (c); i-IGT vs NGT, IFG/IGT vs NGT, i-IGT vs i-IFG (d). Adapted from Færch et al. [19] the disposition index, we and others [13, 19, 30, 31] could not find evidence of an appropriate compensatory increase in insulin secretion in individuals progressing from NGT to i-IFG or i-IGT (Fig. 1c). Only individuals progressing from NGT to IFG/IGT seem to exhibit a compensatory increase in insulin secretion [19, 32] (Fig. 2c). This could indicate that more severe abnormalities in both the fasting and the postprandial states may be necessary for increasing the insulin-secretory capacity of pancreatic beta cells. However, it should be noted that a short-term compensatory increase in insulin secretion may be followed by exhaustion with time.

Glucagon secretion Glucagon acts as a counter-regulatory hormone to insulin and may therefore play an essential role in type 2 diabetes pathophysiology. Many patients with type 2 diabetes have increased alpha cell mass [33], which contributes to disproportionately elevated fasting glucagon levels $[2$, 3]. Whether these alterations in glucagon secretion are secondary to other metabolic defects in type 2 diabetes or whether they are primary to the disease is not fully understood.

Only few studies have examined glucagon secretion in individuals with impaired glucose regulation. Two studies $[34,35]$ found near-normal fasting and post-OGTT glucagon levels in individuals with IGT (i-IGT and IFG/IGT together). However, when glucagon concentration was related to the ambient levels of insulin or glucose, they found a reduced suppression of glucagon secretion [34, 35]. Two other studies [36, 37] demonstrated elevated glucagon levels in both obese and non-obese IGT individuals, and we also previously reported that both individuals with i-IFG and individuals with i-IGT had significantly elevated fasting and post-OGTT glucagon concentrations compared with individuals with NGT [13]. Overall, these findings in individuals with impaired glucose regulation indicate that abnormal pancreatic alpha cell function may be a signifi- 
cant and early abnormality in the pathogenesis of type 2 diabetes. However, since glucagon levels are increased in both individuals with i-IFG and individuals with i-IGT, the different pathogenesis of fasting vs postprandial glucose regulation may not be explained by differences in glucagon secretion.

Gut

Few studies have published data on incretin hormone secretion in individuals with i-IFG and i-IGT $[13,32]$. We previously reported that individuals with i-IFG may compensate for a reduced beta cell function by increasing the secretion of GLP-1 [13]. This finding was contrasted by the European Network on Functional Genomics of Type 2 Diabetes (EUGENE2) study [32], which found reduced secretion of GLP-1 during an OGTT in individuals with iIFG. In the EUGENE2 study [32], first-phase insulin response was not impaired in individuals with $\mathrm{i}-\mathrm{IFG}$, which might explain why GLP-1 secretion was not compensatingly elevated [13]. Also, the fact that the EUGENE2 study [32] was a multicentre study with a very heterogeneous population might have contributed to the different findings. GIP levels were normal in i-IFG individuals in our study [13] and in the EUGENE2 study [32].

Individuals with i-IGT seem to be characterised by a reduced secretion of GIP during OGTTs [13]. Studies in individuals with IGT (i-IGT and IFG/IGT together) also showed partial impaired incretin effect $[38,39]$ as well as reduced GIP [40] and GLP-1 secretion [41].

Despite observed alterations in gut incretin hormone secretion in individuals with NGT and prediabetes [13, 32, $38,39,41]$, the current thought is that the reduced incretin hormone secretion and action observed in type 2 diabetes is likely to be secondary to other hormonal and metabolic alterations, such as hyperglucagonaemia [42]. Prospective observational studies in individuals progressing from NGT to type 2 diabetes are needed to establish the natural history of incretin hormones in the development of type 2 diabetes.

Adipose tissue

Adipose tissue is an active endocrine organ, secreting several products into the bloodstream, of which adipokines (e.g. leptin, adiponectin, resistin and visfatin) and cytokines (e.g. TNF- $\alpha$, IL-1 and IL-6) are involved in obesity-related insulin resistance and inflammation [7]. In patients with type 2 diabetes, basal NEFA levels are often increased [5], lipolysis in adipose tissue is not adequately inhibited by insulin [8] and lipid oxidation is increased [24]. Only a single study has examined the role of the adipose tissue in the prediabetic states i-IFG and i-IGT [43]. It found that both individuals with i-IFG and individuals with i-IGT had increased resistance to the lipolytic action of insulin in the adipocytes. However, individuals with i-IFG seemed to be able to compensate for this adipocyte insulin resistance by increasing their basal insulin secretion, thereby keeping NEFA levels in the normal range. In contrast, those with iIGT had elevated NEFA levels, indicating an enhanced rate of lipolysis despite normal basal insulin levels [43]. More studies are needed to confirm these findings, but also the role of adipocytokines in the development of i-IFG and iIGT deserves attention in future studies.

\section{Brain and kidney}

Both brain and kidney may play important roles in type 2 diabetes pathophysiology [10], but no studies have yet examined the function of these organs in relation to the development of the different prediabetic conditions.

\section{Summary}

The pathophysiological characteristics of i-IFG, i-IGT and IFG/IGT are summarised in Table 1.

\section{Aetiology of i-IFG, i-IGT and IFG/IGT}

\section{Environmental factors}

Environmental factors play an enormous role in type 2 diabetes aetiology. However, only few studies have examined the individual and isolated roles of common environmental risk factors in the development of fasting and postprandial hyperglycaemia (i-IFG and i-IGT).

Physical inactivity The effect of physical inactivity on glucose metabolism predominantly includes impairments of peripheral insulin-stimulated glucose uptake (i.e. peripheral insulin resistance) [44, 45]. The findings that physical activity is associated with $2 \mathrm{~h}$ plasma glucose (2hPG) levels and i-IGT, but not with fasting plasma glucose (FPG) levels and i-IFG [19, 46-48] support this notion.

Diet In addition to physical activity, diet plays a central role in type 2 diabetes aetiology. In particular, the total dietary fat amount and intake of saturated fat increase the risk of developing impaired glucose regulation and type 2 diabetes $[49,50]$, while high intakes of dietary fibre and wholegrain products decrease the risk [51]. Since we do not eat single dietary components, but mixed meals, analyses of dietary patterns [52] or dietary scores [53] have attracted much attention during recent years. Recently, we found that the dietary quality of individuals who developed i-IGT was lower than that of those who developed i-IFG and IFG/IGT 
Table 1 Pathophysiology of the prediabetic states

${ }^{a}$ Disposition index is the firstphase insulin response adjusted for peripheral insulin resistance

?, Not studied

\begin{tabular}{|c|c|c|c|}
\hline Pathophysiology & i-IFG & i-IGT & IFG/IGT \\
\hline \multicolumn{4}{|l|}{ Muscle } \\
\hline Insulin sensitivity & Unaltered & Reduced & Reduced \\
\hline \multicolumn{4}{|l|}{ Liver } \\
\hline Insulin sensitivity & Reduced & Unaltered & Reduced \\
\hline Hepatic glucose production & Elevated & Unaltered & Elevated \\
\hline \multicolumn{4}{|l|}{ Pancreas } \\
\hline First-phase insulin response & Reduced & Reduced or unaltered & Reduced \\
\hline Disposition index ${ }^{\mathrm{a}}$ & Reduced & Reduced & Reduced \\
\hline Glucagon secretion & Elevated & Elevated & Elevated \\
\hline \multicolumn{4}{|l|}{ Gut } \\
\hline GLP-1 secretion & Reduced or elevated & Reduced or unaltered & $?$ \\
\hline GIP secretion & Unaltered & Reduced or unaltered & $?$ \\
\hline \multicolumn{4}{|l|}{ Adipose tissue } \\
\hline Insulin sensitivity & Reduced & Reduced & $?$ \\
\hline NEFA release & Unaltered & Elevated & $?$ \\
\hline Adipocytokine release & $?$ & $?$ & $?$ \\
\hline Brain & $?$ & $?$ & $?$ \\
\hline Kidney & $?$ & $?$ & $?$ \\
\hline
\end{tabular}

[19]. Moreover, in the Inter99 study a dietary pattern consisting of high intakes of, for example, high-fat meats, mayonnaise, potatoes and butter predicted an increase in $2 \mathrm{hPG}$ levels, but not in FPG levels at 5 years of follow-up [54]. In addition, the Hoorn study [55] and the Finnish and Dutch cohorts of the Seven Countries Study [49] found associations between dietary factors and $2 \mathrm{hPG}$ levels, but they did not examine the relationship between diet and FPG levels. Together these findings support the idea that diet predominantly affects mechanisms associated with peripheral insulin action, for instance modification of membrane phospholipids [56].

Smoking Smoking increases the risk of type 2 diabetes in both men and women [57]. We recently found that smoking was associated with elevated FPG levels in men but not in women, whereas $2 \mathrm{hPG}$ levels were not affected by smoking [46]. In contrast, smoking was associated with elevated $2 \mathrm{hPG}$ levels in men in the Hoorn study [55]. The effect of smoking on glucose metabolism may be mediated through a modification of body composition [58], but smoking may also cause long-lasting and chronic impairments of both insulin secretion and insulin sensitivity, for instance because of damage caused by reactive oxygen species [59]. In addition, smoking may affect lipid metabolism. For instance, a significant relationship between smoking and hepatic lipase activity (fatty acid release from the liver) has been found [60]. This may be related to the hepatic insulin resistance observed in i-IFG individuals [14, 25].
Heritability

Although environmental factors are important determinants for type 2 diabetes, genetic components may be necessary for the disease to develop. Recently, we found that a family history of diabetes was associated with elevated FPG levels, but not $2 \mathrm{hPG}$ levels $[19,46]$. Several genes may contribute to this effect of family history of diabetes. In the following, we will discuss potential candidates.

The strongest association with type 2 diabetes has been observed for variants in the gene encoding transcription factor 7 like-2 (TCF7L2) [61]. Suggested mechanisms include impaired insulin secretion, blunted incretin effects, hepatic insulin resistance, enhanced rate of EGP and elevated FPG levels [62, 63], all features associated with the development of i-IFG and IFG/IGT. However, variants in TCF7L2 have also been associated with elevated $2 \mathrm{hPG}$ levels [63], which makes it difficult to use variants in this gene to discriminate between individuals developing i-IFG and i-IGT.

Other genes with potential influence on fasting glucose regulation are MTNRIB [64-66], GCK [67, 68], GCKR [69, 70] and G6PC2 [71-73]. These risk variants seem to have cumulative effects on FPG levels [66] (Fig. 3). In addition to being associated with FPG levels, the $G$ allele of MTNR1B rs10830963 also increases the odds of having iIFG and IFG/IGT but not i-IGT [64]. This variant may therefore be interesting with respect to identifying individuals who are at increased risk of developing isolated defects in fasting glucose regulation. 


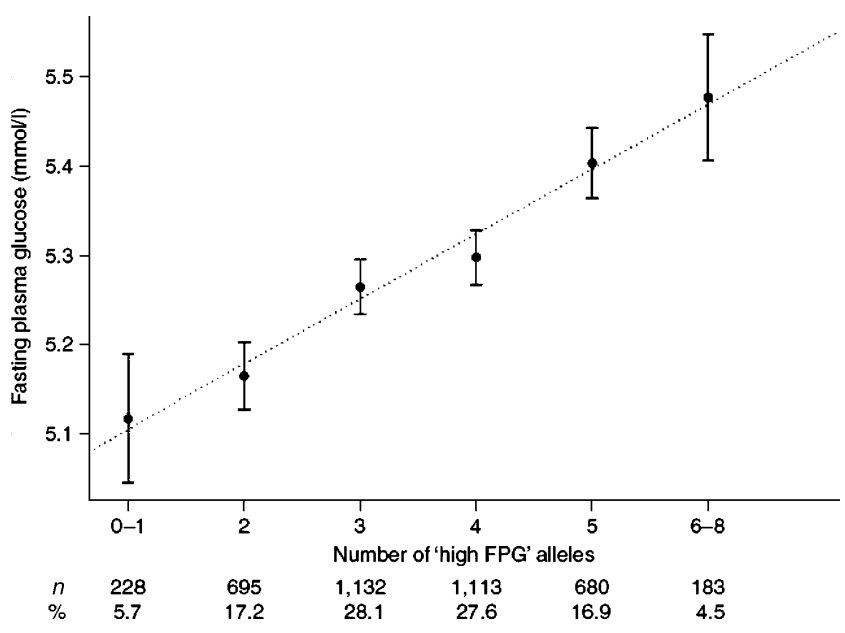

Fig. 3 Cumulative effects of MTNR1B rs1387153, G6PC2 rs560887, GCKR rs1260326 (P446L) and GCK rs1799884 (-30G) variants on FPG levels in the Data from an Epidemiological Study on the Insulin Resistance syndrome (DESIR) study. Data are means (95\% CI). The $\beta$ coefficient $(\beta=0.07,95 \%$ CI $0.06-0.08$, adjusted for age, sex and BMI, $p=8 \times 10^{-33}$ ) corresponds to the increase in FPG levels by additional 'high FPG' alleles. Adapted with permission from Bouatia-Naji et al. [66]

No gene variants have been exclusively associated with 2hPG levels or i-IGT, but variants in PPARG and FTO have been associated with insulin sensitivity [74, 75], a key defect of i-IGT. However, since PPARG variants are not related to $2 \mathrm{hPG}$ levels $[75,76]$, and $F T O$ variants are associated with elevated FPG levels and hepatic insulin resistance [77], neither of these gene variants is likely to be involved in the development of i-IGT.

Recently, a Danish group showed that it is not possible to effectively discriminate between individuals with NGT and type 2 diabetes by combining the effects of 19 validated type 2 diabetes gene variants [78]. Thus, it is still too early to make individualised prevention of type 2 diabetes based on genetic information.

Sex and anthropometry

Inverse relationships between height and $2 \mathrm{hPG}$ levels have been demonstrated in both men and women [46, 79], indicating that short individuals are more likely to be diagnosed with i-IGT than with i-IFG. Low birthweight is strongly related to short adult stature [80] as well as to the development of IGT and type 2 diabetes later in life [8183]. Significant associations between low birthweight and adult FPG levels have also been demonstrated [84, 85], which indicates that low birthweight affects several pathways involved in glucose regulation. Whether low birthweight is more closely related to the development of i-IGT than to the development of i-IFG is not yet clear.

It is well recognised that the risk of developing type 2 diabetes is higher in men than in women [86, 87]. In addition, the prevalence of $\mathrm{i}$-IFG is highest in men, whereas the prevalence of i-IGT is highest in women [17, 19, 79, 88]. Compared with men, women have higher postprandial and post-OGTT levels of plasma glucose, insulin, GIP and GLP-1 [41, 88, 89]. Differences in the ability to dispose of the ingested $75 \mathrm{~g}$ glucose because of differences in height and thereby muscle mass between men and women could explain the sex differences in the prevalence of i-IGT, as suggested by Sicree et al. [79]. Likewise, differences in metabolically active muscle mass between short and tall individuals exposed to the same amount of glucose may also partly explain the effect of height on $2 \mathrm{hPG}$ levels. Future studies using different amounts of glucose during OGTTs in men and women with different body composition might bring us closer to an understanding of the link between sex, anthropometry and $2 \mathrm{hPG}$ levels.

\section{Summary}

The aetiological factors associated with elevated fasting and/or $2 \mathrm{hPG}$ levels are summarised in Table 2.

\section{Implications for prevention and treatment of type 2 diabetes}

\section{Prevention}

When type 2 diabetes has become manifest, it is most often too late to reverse the glucotoxic effects of hyperglycaemia on beta cell function. Interventions to delay or even prevent the development of type 2 diabetes therefore seem more important than treatment, regarding population health and the burden of healthcare costs.

Since individuals with i-IFG and i-IGT are characterised by different pathophysiological features, the optimal prevention of type 2 diabetes may differ between these groups of individuals. For instance, it is not likely that lifestyle interventions mainly targeting peripheral insulin sensitivity are as equally effective in individuals with iIFG as in those with i-IGT [90, 91]. Randomised followup studies with different intervention strategies (e.g. lifestyle intervention, metformin, incretin-based therapy and placebo) in high-risk individuals with i-IFG and i-IGT are needed to clarify whether alternative approaches may improve prevention of type 2 diabetes in those with i-IFG.

The findings that different risk factors may cause elevated plasma glucose levels in men and women [46] and that individuals who develop i-IFG and IFG/IGT are more likely to have a family history of type 2 diabetes [19] may be used in relation to risk assessment in the clinic. If other studies confirm these observations, new sex-specific 
Table 2 Effects of aetiological factors on FPG levels (the development of i-IFG), $2 \mathrm{hPG}$ levels (the development of $\mathrm{i}$-IGT) and combined FPG/2hPG levels (the development of IFG/IGT)

\section{?, Not studied}

\begin{tabular}{llll}
\hline Aetiology & FPG levels (i-IFG) & 2hPG levels (i-IGT) & FPG/2hPG levels (IFG/IGT) \\
\hline Environmental factors & & & \\
Physical inactivity & No effect & Increase & $?$ \\
Low dietary quality & No effect & Increase & No effect \\
Smoking & Increase & No effect or increase & Increase \\
Heritability & & & \\
Family history of diabetes & Increase & No effect & Increase \\
TCF7L2 & Increase & Increase & $?$ \\
$M T N R 1 B$ & Increase & No effect & $?$ \\
$G C K$ & Increase & Increase & $?$ \\
$G C K R$ & Increase & No effect & $?$ \\
$G 6 P C 2$ & Increase & No effect & $?$ \\
$F T O$ & Increase & No effect & $?$ \\
$P P A R G$ & Increase & No effect & $?$ \\
Sex and anthropometry & & & \\
Male sex & Increase & Decrease & No effect \\
Low birthweight & Increase & Increase & $?$ \\
Short adult stature & No effect & Increase & $?$ \\
\hline
\end{tabular}

screening algorithms could be developed to improve prediction and prevention of type 2 diabetes.

\section{Treatment}

To clarify the pathophysiology of different type 2 diabetes phenotypes, there is a need for prospective studies in individuals developing diabetes dominated by defects in fasting glucose regulation vs defects in postprandial glucose regulation. Based on the current studies of individuals with i-IFG and i-IGT, it is likely that patients with isolated defects in fasting glucose regulation may benefit from medication targeting hepatic insulin sensitivity and beta cell function, whereas those with predominantly defects in $2 \mathrm{hPG}$ levels may benefit from medication or lifestyle changes targeting peripheral insulin sensitivity.

IFG and IGT as diagnostic criteria

About 10 years ago, the new definition of i-IFG gave rise to an increased focus on the pathophysiological differences between i-IFG and i-IGT, but recently it has been widely debated whether the use of i-IFG, i-IGT and IFG/IGT as diagnostic criteria should be reconsidered [92-94]. One of the major reasons is that the prediabetic states are likely to be continuums of impaired glucose regulation rather than being binary states. Furthermore, the definitions of i-IFG, iIGT and IFG/IGT are based on rather arbitrary cut-off points from OGTTs with limited reproducibility [95]. However, even though the diagnostic criteria for diabetes and impaired glucose regulation may be changed, it is still important to bear in mind that individuals with elevated fasting glucose levels differ in aetiology and pathophysiology from those with elevated postprandial glucose levels and therefore may require different prevention and treatment.

\section{Conclusions}

In conclusion, the pathophysiology of i-IFG seem to include the following key defects: reduced hepatic insulin sensitivity, stationary beta cell dysfunction and/or chronic low beta cell mass, altered GLP-1 secretion and inappropriately elevated glucagon secretion. Conversely, the prediabetic state i-IGT is characterised by reduced peripheral insulin sensitivity, near-normal hepatic insulin sensitivity, progressive loss of beta cell function, reduced secretion of GIP and inappropriately elevated glucagon secretion. Individuals developing IFG/IGT exhibit severe defects in both peripheral and hepatic insulin sensitivity, as well as a progressive loss of beta cell function.

The aetiologies of i-IFG and i-IGT also seem to differ, with i-IFG being predominantly related to genetic factors, smoking and male sex, while i-IGT is predominantly related to physical inactivity, unhealthy diet and abnormalities associated with short adult stature. Aetiological factors associated with IFG/IGT have not yet been examined.

Since the transition from the prediabetic states to overt type 2 diabetes is characterised by a non-reversible vicious cycle that includes severe deleterious effects on glucose metabolism, there are good reasons to use the wellestablished aetiological and pathophysiological differences in $\mathrm{i}-\mathrm{IFG}$ and $\mathrm{i}$-IGT to design individualised preventive strategies. 
Acknowledgements We would like to thank the Danish Strategic Research Council, the Danish Ministry of Science, Technology and Innovation, the Danish Diabetes Association, the Novo Nordisk Foundation, the Foundation of Gerda and Aage Haensch, and the EXGENESIS EU consortium.

Duality of interest K. Borch-Johnsen is head of the Steno Diabetes Center, a hospital integrated into the Danish National Health Care Service, but owned by Novo Nordisk. K. Borch-Johnsen holds shares in Novo Nordisk. The other authors declare that they have no duality of interest associated with this manuscript.

\section{References}

1. Leahy JL (2005) Pathogenesis of type 2 diabetes mellitus. Arch Med Res 36:197-209

2. Unger RH, Aguilar-Parada E, Müller WA, Eisentraut AM (1970) Studies of pancreatic alpha cell function in normal and diabetic subjects. J Clin Invest 49:837-848

3. Dunning BE, Gerich JE (2007) The role of alpha-cell dysregulation in fasting and postprandial hyperglycemia in type 2 diabetes and therapeutic implications. Endocr Rev 28:253-283

4. Vilsbøll T, Knop FK, Krarup T et al (2003) The pathophysiology of diabetes involves a defective amplification of the late-phase insulin response to glucose by glucose-dependent insulinotropic polypeptide-regardless of etiology and phenotype. J Clin Endocrinol Metab 88:4897-4903

5. Golay A, Swislocki AL, Chen YD, Reaven GM (1987) Relationships between plasma-free fatty acid concentration, endogenous glucose production, and fasting hyperglycemia in normal and noninsulin-dependent diabetic individuals. Metabolism 36:692-696

6. Stumvoll M, Chintalapudi U, Perriello G, Welle S, Gutierrez O, Gerich J (1995) Uptake and release of glucose by the human kidney. Postabsorptive rates and responses to epinephrine. J Clin Invest 96:2528-2533

7. Rasouli N, Kern P (2008) Adipocytokines and the metabolic complications of obesity. J Clin Endocrinol Metab 93(11 Suppl 1):s64-s73

8. Basu A, Basu R, Shah P, Vella A, Rizza RA, Jensen MD (2001) Systemic and regional free fatty acid metabolism in type 2 diabetes. Am J Physiol Endocrinol Metab 280:E1000-E1006

9. Obici S, Zhang BB, Karkanias G, Rossetti L (2002) Hypothalamic insulin signaling is required for inhibition of glucose production. Nat Med 8:1376-1382

10. DeFronzo RA (2009) Banting Lecture. From the triumvirate to the ominous octet: a new paradigm for the treatment of type 2 diabetes mellitus. Diabetes 58:773-795

11. O'Rahilly S, Hattersley A, Vaag A, Gray H (1994) Insulin resistance as the major cause of impaired glucose tolerance: a selffulfilling prophesy? Lancet 344:585-589

12. DeFronzo RA (2004) Pathogenesis of type 2 diabetes mellitus. Med Clin North Am 88:787-835

13. Færch K, Vaag A, Holst J, Glümer C, Pedersen O, Borch-Johnsen K (2008) Impaired fasting glycaemia vs impaired glucose tolerance: similar impairment of pancreatic alpha and beta cell function but differential roles of incretin hormones and insulin action. Diabetologia 51:853-861

14. Abdul-Ghani MA, Jenkinson CP, Richardson DK, Tripathy D, DeFronzo RA (2006) Insulin secretion and action in subjects with impaired fasting glucose and impaired glucose tolerance-results from the veterans administration genetic epidemiology study. Diabetes 55:1430-1435

15. Weyer C, Bogardus C, Pratley RE (1999) Metabolic characteristics of individuals with impaired fasting glucose and/or impaired glucose tolerance. Diabetes 48:2197-2203
16. Meyer C, Szoke E, Pimenta W et al (2006) Different mechanisms for impaired fasting glucose and impaired postprandial glucose tolerance in humans. Diabetes Care 29:1909-1914

17. Tripathy D, Almgren P, Tuomi T, Groop L (2004) Contribution of insulin-stimulated glucose uptake and basal hepatic insulin sensitivity to surrogate measures of insulin sensitivity. Diabetes Care 27:2204-2210

18. Wasada T, Kuroki H, Katsumori K et al (2004) Who are more insulin resistant, people with IFG or people with IGT? Diabetologia 47:759-760

19. Færch K, Vaag A, Holst JJ, Hansen T, Jørgensen T, BorchJohnsen K (2009) Natural history of insulin sensitivity and insulin secretion in the progression from normal glucose tolerance to impaired fasting glycemia and impaired glucose tolerance- the Inter99 study. Diabetes Care 32:439-444

20. Abdul-Ghani MA, Sabbah M, Kher J, Minuchin O, Vardi P, Raz I (2006) Different contributions of insulin resistance and beta-cell dysfunction in overweight Israeli Arabs with IFG and IGT. Diabetes Metab Res Rev 22:126-130

21. Novoa FJ, Boronat M (2005) Saavedra P et al Differences in cardiovascular risk factors, insulin resistance, and insulin secretion in individuals with normal glucose tolerance and in subjects with impaired glucose regulation: The Telde study. Diabetes Care 28:2388-2393

22. DeFronzo RA, Tobin JD, Andres R (1979) Glucose clamp technique: a method for quantifying insulin secretion and resistance. Am J Physiol 237:E214-E223

23. Man CD, Toffolo G, Basu R, Rizza RA, Cobelli C (2008) Use of labeled oral minimal model to measure hepatic insulin sensitivity. Am J Physiol Endocrinol Metab 295:E1152-E1159

24. Vaag A, Alford F, Henriksen FL, Christopher M, Beck-Nielsen H (1995) Multiple defects of both hepatic and peripheral intracellular glucose processing contribute to the hyperglycaemia of NIDDM. Diabetologia 38:326-336

25. Bock G, Chittilapilly E, Basu R et al (2007) Contribution of hepatic and extrahepatic insulin resistance to the pathogenesis of impaired fasting glucose: role of increased rates of gluconeogenesis. Diabetes 56:1703-1711

26. Butler AE, Janson J, Bonner-Weir S, Ritzel R, Rizza RA, Butler PC (2003) Beta-cell deficit and increased beta-cell apoptosis in humans with type 2 diabetes. Diabetes 52:102-110

27. Qiao Q (2005) Are insulin resistance, impaired fasting glucose and impaired glucose tolerance all equally strongly related to age? Diabet Med 22:1476-1481

28. Turner RC, Cull CA, Frighi V, Holman RR (1999) Glycemic control with diet, sulfonylurea, metformin, or insulin in patients with type 2 diabetes mellitus: progressive requirement for multiple therapies (UKPDS 49). UK Prospective Diabetes Study (UKPDS) Group. JAMA 281:2005-2012

29. Chang-Chen K, Mullur R, Bernal-Mizrachi E (2008) Beta-cell failure as a complication of diabetes. Rev Endocr Metab Disord 9:329-343

30. Festa A, Williams K, D'Agostino R Jr, Wagenknecht LE, Haffner SM (2006) The natural course of beta cell function in nondiabetic and diabetic individuals: the Insulin Resistance Atherosclerosis Study. Diabetes 55:1114-1120

31. Ahrén B, Pacini G (1997) Impaired adaptation of first-phase insulin secretion in postmenopausal women with glucose intolerance. Am J Physiol 273:E701-E707

32. Laakso M, Zilinskaite J, Hansen T et al (2008) Insulin sensitivity, insulin release and glucagon-like peptide-1 levels in persons with impaired fasting glucose and/or impaired glucose tolerance in the EUGENE2 study. Diabetologia 51:502-511

33. Gromada J, Franklin I, Wollheim CB (2007) Alpha-cells of the endocrine pancreas: 35 years of research but the enigma remains. Endocr Rev 28:84-116 
34. Ahrén B, Larsson H (2001) Impaired glucose tolerance (IGT) is associated with reduced insulin-induced suppression of glucagon concentrations. Diabetologia 44:1998-2003

35. Abdul-Ghani MA, DeFronzo RA (2007) Fasting hyperglycemia impairs glucose- but not insulin-mediated suppression of glucagon secretion. J Clin Endocrinol Metab 92:1778-1784

36. Mitrakou A, Kelley D, Mokan M et al (1992) Role of reduced suppression of glucose production and diminished early insulin release in impaired glucose tolerance. N Engl J Med 326:22-29

37. Henkel E, Menschikowski M, Koehler C, Leonhardt W, Hanefeld M (2005) Impact of glucagon response on postprandial hyperglycemia in men with impaired glucose tolerance and type 2 diabetes mellitus. Metabolism 54:1168-1173

38. Fritsche A, Stefan N, Hardt E, Häring H, Stumvoll M (2000) Characterisation of beta-cell dysfunction of impaired glucose tolerance: evidence for impairment of incretin-induced insulin secretion. Diabetologia 43:852-858

39. Muscelli E, Mari A, Casolaro A et al (2008) Separate impact of obesity and glucose tolerance on the incretin effect in normal subjects and type 2 diabetic patients. Diabetes 57:1340-1348

40. Ahrén B, Larsson H, Holst JJ (1997) Reduced gastric inhibitory polypeptide but normal glucagon-like peptide 1 response to oral glucose in postmenopausal women with impaired glucose tolerance. Eur J Endocrinol 137:127-131

41. Toft-Nielsen MB, Damholt MB, Madsbad S et al (2001) Determinants of the impaired secretion of glucagon-like peptide1 in type 2 diabetic patients. J Clin Endocrinol Metab 86:37173723

42. Vollmer K, Holst JJ, Baller B et al (2008) Predictors of incretin concentrations in subjects with normal, impaired, and diabetic glucose tolerance. Diabetes 57:678-687

43. Abdul-Ghani MA, Molina-Carrion M, Jani R, Jenkinson C, DeFronzo R (2008) Adipocytes in subjects with impaired fasting glucose and impaired glucose tolerance are resistant to the antilipolytic effect of insulin. Acta Diabetol 45:147-150

44. Balkau B, Mhamdi L, Oppert JM et al (2008) Physical activity and insulin sensitivity: the RISC Study. Diabetes 57:2613-2618

45. Assah FK, Brage S, Ekelund U, Wareham NJ (2008) The association of intensity and overall level of physical activity energy expenditure with a marker of insulin resistance. Diabetologia 51:1399-1407

46. Færch K, Vaag A, Witte DR, Jørgensen T, Pedersen O, BorchJohnsen K (2009) Predictors of future fasting and 2-hour postOGTT plasma glucose levels in middle-aged men and womenthe Inter99 study. Diabet Med 26:377-383

47. Healy GN, Dunstan DW, Shaw JE, Zimmet PZ, Owen N (2006) Beneficial associations of physical activity with 2-h but not fasting blood glucose in Australian adults. Diabetes Care 29:2598-2604

48. Assah FK, Ekelund U, Brage S, Mbanya JC, Wareham NJ (2009) free-living physical activity energy expenditure is strongly related to glucose intolerance in Cameroonian adults independently of obesity. Diabetes Care 32:367-369

49. Feskens EJ, Virtanen SM, Räsänen L et al (1995) Dietary factors determining diabetes and impaired glucose tolerance. A 20 -year follow-up of the Finnish and Dutch cohorts of the Seven Countries Study. Diabetes Care 18:1104-1112

50. Van Dam RM, Stampfer M, Willett WC, Hu FB, Rimm EB (2002) Dietary fat and meat intake in relation to risk of type 2 diabetes in men. Diabetes Care 25:417-424

51. Pereira MA, Jacobs DR, Pins JJ et al (2002) Effect of whole grains on insulin sensitivity in overweight hyperinsulinemic adults. Am J Clin Nutr 75:848-855

52. Lau C, Glümer C, Toft U et al (2008) Identification and reproducibility of dietary patterns in a Danish cohort: the Inter99 study. Br J Nutr 99:1089-1098
53. Toft U, Kristoffersen LH, Lau C, Borch-Johnsen K, Jorgensen T (2006) The Dietary Quality Score: validation and association with cardiovascular risk factors: the Inter99 study. Eur J Clin Nutr 61:270-278

54. Lau C, Toft U, Tetens I et al (2009) Dietary patterns predict changes in two-hour post-oral glucose tolerance test plasma glucose concentrations in middle-aged adults. J Nutr 139:588-593

55. Mooy JM, Grootenhuis PA, de Vries H et al (1995) Prevalence and determinants of glucose intolerance in a Dutch caucasian population. The Hoorn Study. Diabetes Care 18:1270-1273

56. Smith U (1994) Carbohydrates, fat, and insulin action. Am J Clin Nutr 59(Suppl 3):686S-689S

57. Feskens EJM, Kromhout D (1989) Cardiovascular risk factors and the 25-year incidence of diabetes mellitus in middle-aged men. The Zutphen Study. Am J Epidemiol 130:1101-1108

58. Bamia C, Trichopoulou A, Lenas D, Trichopoulos D (2004) Tobacco smoking in relation to body fat mass and distribution in a general population sample. Int $\mathrm{J}$ Obes Relat Metab Disord 28:1091-1096

59. Song F, Jia W, Yao Y et al (2007) Oxidative stress, antioxidant status and DNA damage in patients with impaired glucose regulation and newly diagnosed type 2 diabetes. Clin Sci 112:599-606

60. Kong C, Nimmo L, Elatrozy T et al (2001) Smoking is associated with increased hepatic lipase activity, insulin resistance, dyslipidaemia and early atherosclerosis in Type 2 diabetes. Atherosclerosis $156: 373-378$

61. Lyssenko V (2008) The transcription factor 7-like 2 gene and increased risk of type 2 diabetes: an update. Curr Opin Clin Nutr Metab Care 11:385-392

62. Lyssenko V, Lupi R, Marchetti P et al (2007) Mechanisms by which common variants in the TCF7L2 gene increase risk of type 2 diabetes. J Clin Invest 117:2155-2163

63. Wegner L, Hussain MS, Pilgaard K et al (2008) Impact of TCF7L2 rs7903146 on insulin secretion and action in young and elderly Danish twins. J Clin Endocrinol Metab 93:4013-4019

64. Sparsø T, Bonnefond A, Andersson E et al (2009) G-allele of intronic rs10830963 in MTNR1B confers increased risk of impaired fasting glycemia and type 2 diabetes through an impaired glucose-stimulated insulin release. Diabetes 58:14501456

65. Lyssenko V, Nagorny CLF, Erdos MR et al (2009) Common variant in MTNR1B associated with increased risk of type 2 diabetes and impaired early insulin secretion. Nat Genet 41:82-88

66. Bouatia-Naji N, Bonnefond A, Cavalcanti-Proenca C et al (2009) A variant near MTNR1B is associated with increased fasting plasma glucose levels and type 2 diabetes risk. Nat Genet 41:89-94

67. Rose CS, Ek J, Urhammer SA et al (2005) A -30G\&gt;A polymorphism of the beta-cell-specific glucokinase promoter associates with hyperglycemia in the general population of whites. Diabetes 54:3026-3031

68. Weedon MN, Clark VJ, Qian Y, Ben-Shlomo Y, Timpson N, Ebrahim S et al (2006) A common haplotype of the glucokinase gene alters fasting glucose and birth weight: Association in six studies and population-genetics analyses. Am J Hum Genet 79:991-1001

69. Sparsø T, Andersen G, Nielsen T, Burgdorf K, Gjesing A, Nielsen A et al (2008) The GCKR rs780094 polymorphism is associated with elevated fasting serum triacylglycerol, reduced fasting and OGTT-related insulinaemia, and reduced risk of type 2 diabetes. Diabetologia 51:70-75

70. Orho-Melander M, Melander O, Guiducci C et al (2008) Common missense variant in the glucokinase regulatory protein gene is associated with increased plasma triglyceride and C-reactive protein but lower fasting glucose concentrations. Diabetes $57: 3112-3121$ 
71. Bouatia-Naji N, Rocheleau G, Van-Lommel L et al (2008) A polymorphism within the G6PC2 gene is associated with fasting plasma glucose levels. Science 320:1085-1088

72. Chen WM, Erdos MR, Jackson AU et al (2008) Variations in the G6PC2/ABCB11 genomic region are associated with fasting glucose levels. J Clin Invest 118:2620-2628

73. Hu C, Zhang R, Wang C et al (2009) A genetic variant of G6PC2 is associated with type 2 diabetes and fasting plasma glucose level in the Chinese population. Diabetologia 52:451-456

74. Andreasen CH, Stender-Petersen KL, Mogensen MS et al (2008) Low physical activity accentuates the effect of the FTO rs 9939609 polymorphism on body fat accumulation. Diabetes 57:95-101

75. Ek J, Andersen G, Urhammer SA et al (2001) Studies of the Pro12Ala polymorphism of the peroxisome proliferator-activated receptor-gamma 2 (PPAR-gamma 2) gene in relation to insulin sensitivity among glucose tolerant caucasians. Diabetologia 44:1170-1176

76. Altshuler D, Hirschhorn JN, Klannemark M et al (2000) The common PPAR gamma Pro12Ala polymorphism is associated with decreased risk of type 2 diabetes. Nat Genet 26:76-80

77. Grunnet LG, Brons C, Jacobsen S et al (2009) Increased recovery rates of phosphocreatine and inorganic phosphate after isometric contraction in oxidative muscle fibers and elevated hepatic insulin resistance in homozygous carriers of the A-allele of FTO rs9939609. J Clin Endocrinol Metab 94:596-602

78. Sparsø T, Grarup N, Andreasen C et al (2009) Combined analysis of 19 common validated type 2 diabetes susceptibility gene variants shows moderate discriminative value and no evidence of gene-gene interaction. Diabetologia 52:1308-1314

79. Sicree RA, Zimmet PZ, Dunstan DW, Cameron AJ, Welborn TA, Shaw JE (2008) Differences in height explain gender differences in the response to the oral glucose tolerance test - the AusDiab study. Diabet Med 25:296-302

80. Leger J, Levy-Marchal C, Bloch J et al (1997) Reduced final height and indications for insulin resistance in 20 year olds born small for gestational age: regional cohort study. BMJ 315:341347

81. Ravelli ACJ, van der Meulen JHP, Michels RPJ et al (1998) Glucose tolerance in adults after prenatal exposure to famine. Lancet 351:173-177

82. Hales CN, Barker DJ, Clark PM et al (1991) Fetal and infant growth and impaired glucose tolerance at age 64. BMJ 303:10191022

83. Poulsen P, Vaag AA, Kyvik KO, Møller-Jensen D, Beck-Nielsen $\mathrm{H}$ (1997) Low birth weight is associated with NIDDM in discordant monozygotic and dizygotic twin pairs. Diabetologia 40:439-446

84. Jensen CB, Storgaard H, Dela F, Holst JJ, Madsbad S, Vaag AA (2002) Early differential defects of insulin secretion and action in 19-year-old caucasian men who had low birth weight. Diabetes 51:1271-1280

85. Brøns C, Jensen CB, Storgaard H et al (2008) Mitochondrial function in skeletal muscle is normal and unrelated to insulin action in young men born with low birth weight. J Clin Endocrinol Metab 93:3885-3892

86. Glümer C, Jørgensen T, Borch-Johnsen K (2003) Prevalences of diabetes and impaired glucose regulation in a Danish population: the Inter99 study. Diabetes Care 26:2335-2340

87. Dunstan DW, Zimmet PZ, Welborn TA et al (2002) The rising prevalence of diabetes and impaired glucose tolerance: the Australian Diabetes, Obesity and Lifestyle Study. Diabetes Care 25:829-834

88. Williams JW, Zimmet PZ, Shaw JE et al (2003) Gender differences in the prevalence of impaired fasting glycaemia and impaired glucose tolerance in Mauritius. Does sex matter? Diabet Med 20:915-920

89. Vaag AA, Holst JJ, Vølund A, Beck-Nielsen HB (1996) Gut incretin hormones in identical twins discordant for non-insulindependent diabetes mellitus (NIDDM) - evidence for decreased glucagon-like peptide 1 secretion during oral glucose ingestion in NIDDM twins. Eur J Endocrinol 135:425-432

90. Knowler WC, Barrett-Connor E, Fowler SE et al (2002) Reduction in the incidence of type 2 diabetes with lifestyle intervention or metformin. N Engl J Med 346:393-403

91. Tuomilehto J, Lindström J, Eriksson JG et al (2001) Prevention of type 2 diabetes mellitus by changes in lifestyle among subjects with impaired glucose tolerance. N Engl J Med 344:1343-1350

92. Bloomgarden ZT (2008) American College of Endocrinology PreDiabetes Consensus Conference: Part Three. Diabetes Care 31:2404-2409

93. Genuth S, Kahn R (2008) A step backward - or is it forward? Diabetes Care 31:1093-1096

94. The International Expert Committee (2009) International Expert Committee Report on the role of the A1C assay in the diagnosis of diabetes. Diabetes Care doi:10.2337/dc09-9033

95. Mooy JM, Grootenhuis PA, de Vries H et al (1996) Intraindividual variation of glucose, specific insulin and proinsulin concentrations measured by two oral glucose tolerance tests in a general Caucasian population: the Hoorn Study. Diabetologia 39:298-305 